\title{
DADOS DA OBTENÇÃO DO PÓLEN POR OPERÁRIAS DE Apis mellifera NO MUNICÍPIO DE JI-PARANÁ (RO), BRASIL. ${ }^{1}$
}

\author{
Antonio Carlos MARQUES-SOUZA ${ }^{2}$, Maria Lúcia ABSY ${ }^{2}$, Paulo Afonso \\ Amato CONDÉ ${ }^{3}$, Hugo de Alencar COELHO
}

\begin{abstract}
RESUMO - Foram analisados os pólen corbiculares de operárias de Apis mellifera durante o período de dois anos, no Município de Ji-Parana(RO). Constatou-se que dos 126 tipos polínicos coletados, apenas uma pequena parte $(12,0 \%)$ foram intensamente explorados pelas africanizadas, destacando-se entre eles: Cecropia sp., Orbignya martiana, Poaceae tipo, Cosmos caudatus, Cocos nucifera, Cynometra sp., Mimosa pudica, Cissus sp., etc. que tiveram seus pólen coletados em mais de dez meses. Observou-se que a coleta de pólen pelas Apis, na Amazônia, não está relacionada com as mudanças climáticas e sim com a época de floração das fontes. Fevereiro de 1989 foi o mês onde as operárias mais diversificaram, coletando 41 tipos de plantas. Os meses de março, novembro de 1988 e janeiro de 1990 foram os meses que apresentaram a menor diversificação num total de onze espécies de plantas coletadas pelas operárias.
\end{abstract}

Palavras-chave: Pólen, Apis mellifera, Espécies de plantas

Data on pollen collection by workers of Apis mellifera in the municipality of Ji-Paraná (RO), Brazil.

ABSTRACT - Polen worker corbiculae of Apis mellifera were analised during a period of two years in the municipality of Ji-Paraná(RO). It was verified that of the 126 pollen types collected, only a small part $(12,0 \%)$ was intensely exploited by the africanized honey bee, namely, Cecropia sp., Orbignya martiana, Poaceae tipo, Cosmos caudatus, Cocos nucifera, Cynometra sp., Mimosa pudica, Cissus sp., etc. which had their polen collected for more than ten months. The pollen collected by Apis, at the study site, is not related to climatic change but rather to the flowering period of the sources. The workers collected most pollen types, a total of 41 , in February of 1988; March, November of 1989 and January of 1989 were the months when the workers collected the least number of plant species, a total of eleven types.

Key words: Pollen, Apis mellifera, Plant species

\section{INTRODUÇÃO}

Desde que em 1839 o Padre Antonio Carneiro introduziu no Brasil as primeiras colméias de Apis mellifera iberica, cuja cera seriam utilizadas na confecção de velas (NOGUEIRANETO, 1962 apud CORTOPASSILAURINO, 1982), que o estudo com essas abelhas atingiu um acúmulo de conhecimento suficiente para melhorar, geneticamente, as raças visando uma

Trabalho financiado pela FINEP

2 Instituto Nacional de Pesquisas da Amazônia-INPA, CPBO, Caixa 478 - 69011-970 - ManausAM, Brasil

3 Secretaria de Ciência e Tecnologia de Rondônia - Esplanada das Secretarias

4 Escola Agrotécnica Silvio G. Farias - Rua Monte Castelo, s/n. B. Urupá, 78.930 - JiParaná(RO). 
maior produção de mel. O objetivo inicial que era a fabricação de velas perdeu-se no tempo em detrimento dos outros produtos produzidos por esses Apídeos. Com o passar dos anos, outras raças de Apis foram trazidas para o Brasil, destacando-se entre estas a Apis mellifera mellifera, a Apis mellifera ligustica, a Apis mellifera carnica, a Apis mellifera caucasiana e, finalmente, a Apis mellifera scutellata esta última a preferida dos apicultores devido a sua alta produtividade. KERR (1967) cita que em um experimento com três raças de Apis a produção média de mel em dois meses por colméia foi, respectivamente: $8.760 \mathrm{~kg}$ para Apis mellifera mellifera, $19.220 \mathrm{~kg}$ para Apis mellifera ligustica e $35.450 \mathrm{~kg}$ para Apis mellifera scutellata.

Na Amazônia, as Apis difundiramse pelo processo migratório que é feito naturalmente por elas e pela vinda dos colonos para a região que sempre trazem suas colméias. No município de JiParaná(RO), constatamos que são poucos os moradores que possuem colméias nativas da região, como as Melipona por exemplo. A maioria prefere trabalhar com as Apis, principalmente as africanizadas, isto facilmente explicado pela maior quantidade de mel que elas produzem e pelo amplo conhecimento do seu manuseio.

Visando dar subsídios aos apicultores que desejem domesticar as Apis, é que apresentamos o primeiro levantamento da flora apícola da região que é utilizada pelas abelhas africanizadas para a coleta de pólen.

\section{MATERIAL E MÉTODOS}

As colméias de "africanizadas" objeto desse estudo, estavam localizadas na Escola Agrícola Silvio Gonçalves Farias do Município de Ji-Paraná (RO) (Fig. 1), que possui a particularidade de ter algumas áreas pouco perturbadas e vasta pastagem de gado nos arredores.

Diariamente, de manhã, ou a tarde, seis operárias que retornavam às suas colméias foram capturadas, aleatoriamente, e seus carregamentos de pólen, retirados de suas corbículas, acondicionados em vidros, colocados em câmaras com sílica gel onde permaneciam por 48 hs., sendo em seguida enviados para o Laboratório de Palinologia do INPA em Manaus(AM), onde as amostras de pólen foram acetolisadas (ERDTMAN, 1960), montadas em lâminas com gelatina glicerinada e em seguida lutadas com parafina.

A identificação dos grãos foi feita consultando-se a literatura especializada e por comparação com a coleção de referência do INPA.

Como o objetivo do trabalho era de fazer um levantamento preliminar das espécies vegetais coletadas pelas operárias, não fizemos comparação interespecíficas entre as 16 colméias do apiário, que estavam dispostas em fileiras e separadas uma das outras por 2 metros de distância, e também, não quantificamos os grãos de pólen das amostras.

Chamamos de espécie/dominante $(+)$ quando na amostra existia apenas 


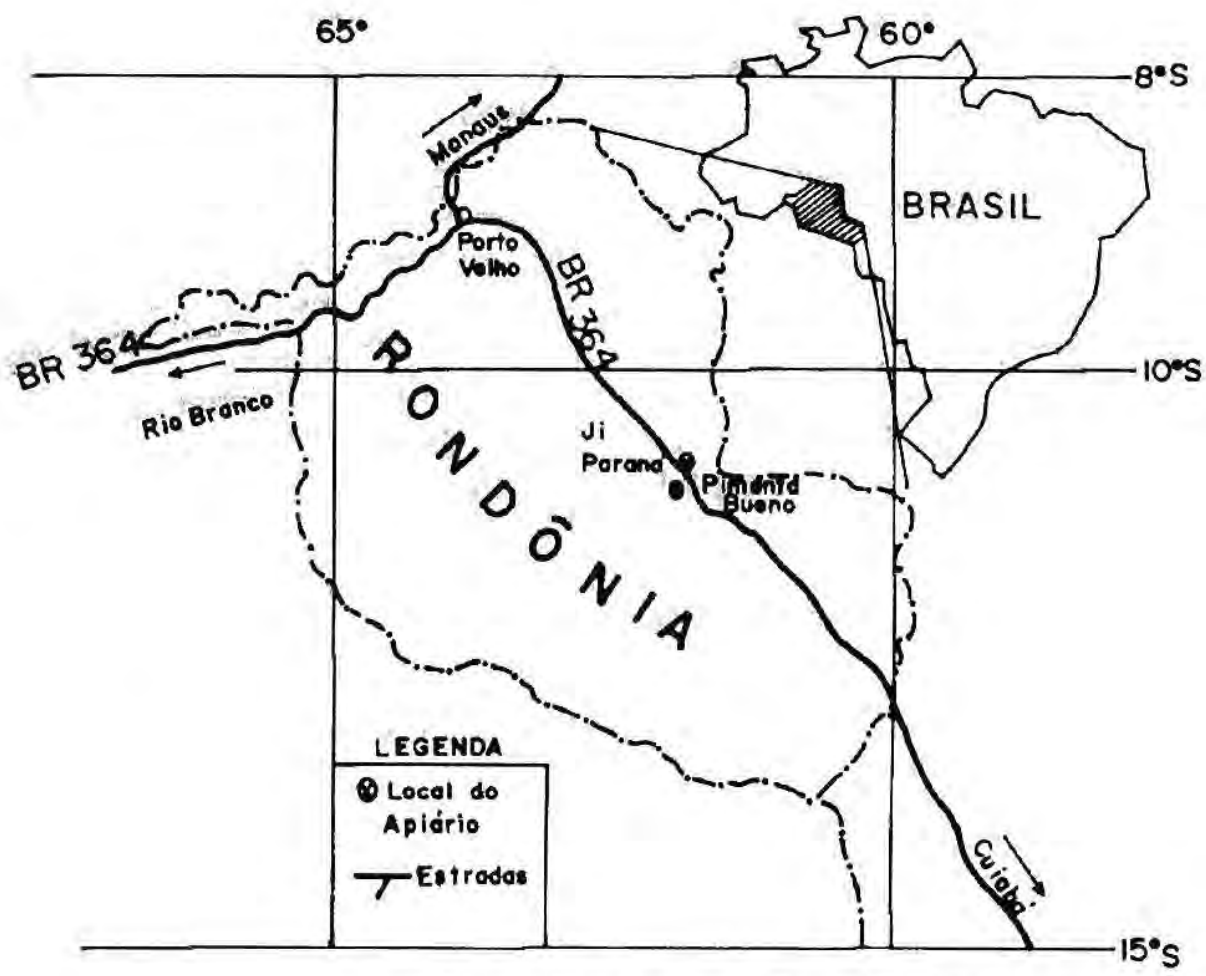

Figura 1. Localização da área do estudo

um tipo polínico. Quando existiam mais de um tipo polínico, denominamos essas plantas coletadas pelas abelhas de espécie/ visitada(x). Ocorria as vezes que um tipo polínico podia ser espécie/visitada(x) durante vários dias e num determinado dia ser espécie/ dominante $(+)$, pois apareceu individualmente na amostra. No caso ficava valendo, para efeito comparativo, a primeira denominação devido a freqüência e quantidade de dias em que a espécie foi coletada pelas operárias.

\section{RESULTADOS}

Na Tabela 1 estão representadas as espécies vegetais que foram coletadas pelas operárias de Apis em dois anos, no período de abril de 1987 a abril de 1989. Entre as famílias vegetais, Arecaceae foi a que apresentou a maior quantidade de espécies coletadas, num total de onze. Dessas espécies, Orbignya martiana foi coletada pelas operárias durante 21 meses, sendo que em treze meses como espécie/dominante $(+)$ e em oito meses espécie/visitada (x). Essa espécie foi constante durante todos os meses de 1987 e só não foi coletada novamente pelas abelhas em julho e outubro de 1988. Nos quatro meses de 1989, Orbignya martiana, teve seu pólen coletado em janeiro e março sendo espécie/dominante(+). Já Cocos 
nucifera foi constante durante 15 meses, sendo que no primeiro ano como espécie/visitada( $\mathrm{x}$ ) em sete meses (abril, maio, junho, julho, agosto, outubro e dezembro) e no ano seguinte em três meses (janeiro, fevereiro e dezembro) espécie/dominante(+). No ano de 1989, Cocos nucifera foi coletada nos quatro meses, sendo que janeiro, fevereiro e abril foi espécie/ dominante $(+)$ e em março espécie/ visitada(x). Outra espécie significativa da família Arecaceae foi Mauritia flexuosa que teve seu pólen coletado pelas operárias durante doze meses, sendo seis meses em 1987 - dos quais março, junho, julho e agosto como espécie/dominante $(+)$ e outubro e dezembro espécie/visitada(x) - e cinco meses de 1988 sendo que em maio, agosto e setembro como espécie/ dominante $(+)$ e em junho e julho como espécie/visitada(x). No ano 1989, Mauritia flexuosa foi coletada no mês de janeiro sendo espécie/visitada(x).

Das outras espécies da família Arecaceae, Euterpe precatoria foi coletada em sete meses dos quais três em 1987, onde agosto como espécie/ $\operatorname{visitada}(\mathrm{x})$, setembro e outubro como espécie/dominante $(+)$; em três meses de 1988 , setembro, outubro e dezembro como espécie/dominante(+) e em janeiro de 1989 como espécie/ dominante (+). As espécies Iriartea sp. e Arecaceae tipo 1 foram coletadas durante seis meses, sendo que a primeira como espécie/dominante $(+)$ nos meses de setembro de 1987, julho e setembro de 1988 e espécie/ visitada(x) em junho e julho de $1987 \mathrm{e}$ junho de 1988. Já Arecaceae tipo 1 foi espécie/dominante $(+)$ em abril e maio de 1987 e em março e abril de 1989. Nos meses de dezembro de 1987 e janeiro de 1988, Arecaceae tipo 1, foi espécie/visitada(x).

A família Mimosaceae veio em seguida com oito espécies de plantas coletadas, onde Mimosa pudica teve seu pólen coletado pelas operárias durante quatorze meses, sendo que em dez meses (maio e dezembro de 1987; janeiro, fevereiro, março, abril, julho, outubro de 1988 e fevereiro e março de 1989) como espécie/visitada(x) e quatro meses (abril de 1987; maio, novembro e dezembro de 1988) espécie/ dominante $(+)$. Ainda dentro dessa família, Leucaena leucocephala teve seu pólen coletado durante nove meses, sendo espécie/dominante $(+)$ em fevereiro e outubro de 1988 e espécie/ visitada(x) em março, abril, maio e setembro de 1988 e nos meses de fevereiro, março e abril de 1989. Já Piptadenia sp. foi coletada em seis meses dos quais abril de 1987, março e abril de 1989 como espécie/ dominante $(+)$ e em maio e dezembro de 1987 e em janeiro de 1988 como espécie/visitada(x).

\section{As famílias Asteraceae e} Caesalpiniaceae tiveram ambas sete espécies coletadas pelas africanizadas. A primeira família teve a espécie Cosmos caudatus coletada durante 17 meses, sendo que em nove meses (abril, maio, junho, outubro e novembro de 1987; abril e agosto de 1988; janeiro e março de 1989) como espécie/ visitada(x) e em oito meses (dezembro 
Tabela 1. Tipos polínicos coletados durante 2 anos por Apis mellifera no Município de Ji-Paraná (RO).

$$
\begin{array}{llll}
1 & 9 & 8 & 7
\end{array}
$$

1988

199809

FAMÍLIA

AMARANTHACEAE

ANACARDIACEAE

APOCYNACEAE

ARALIACEAE

ARECACEAE

ASTERACEAE

\section{ESPÉCIE}

Alternanthera sp. Amaranthus sp.

Tapirira sp. Tipo

Tipo

Didymopanax sp.

Astrocaryum sp. Cocos nucifera

Euterpe precatoria Euterpe sp.

Iriartea sp.

Mauritia flexuosa Maximiliana sp. Orbignya martiana Tipo 1

Tipo 2

Tipo 3

Cosmos caudatus Emilia sonchifolia Latuca sativa Mikania congesta Mikania sp. Tipo

Vernonia scabra

Memora sp.

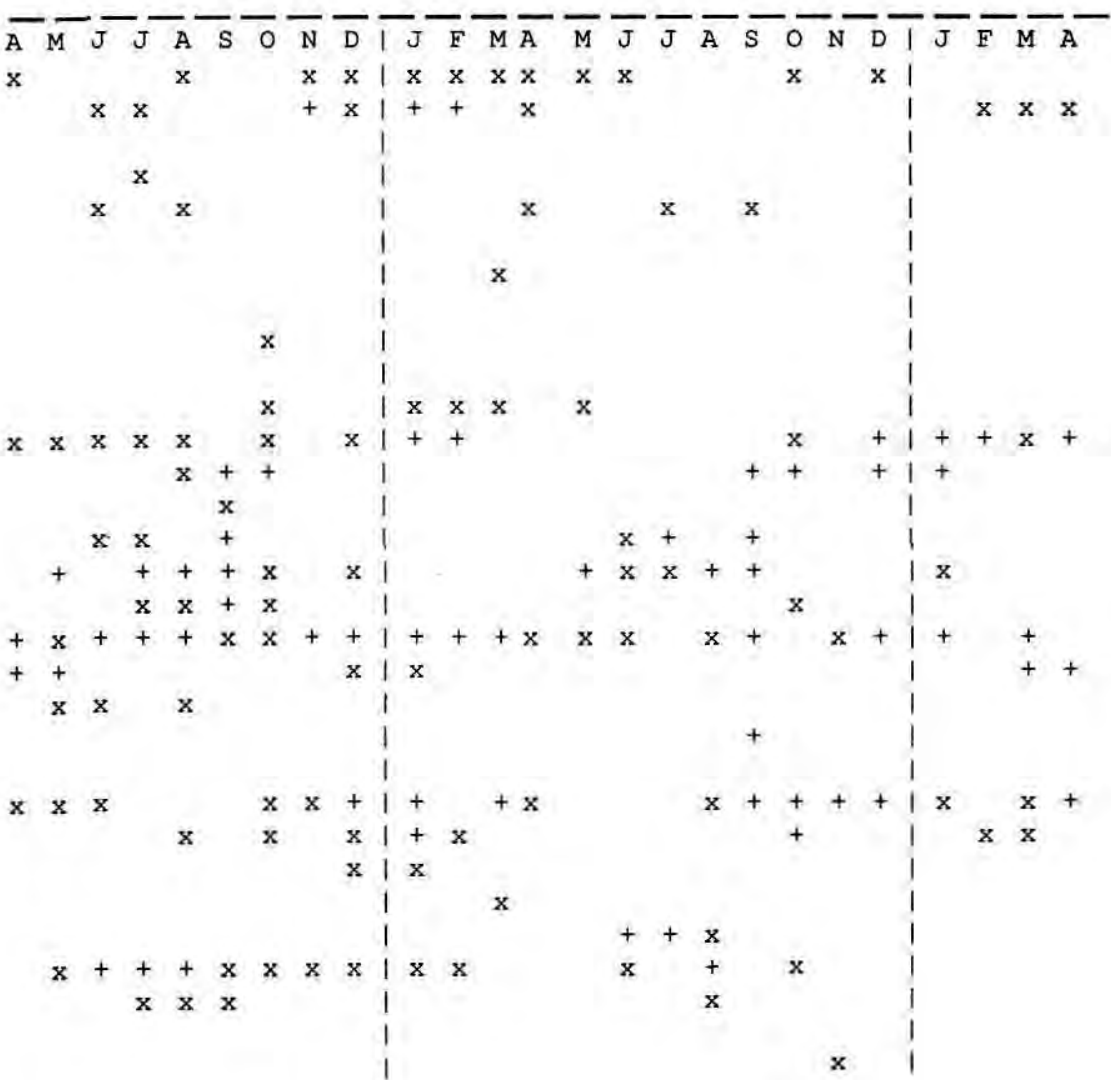




\begin{tabular}{|c|c|c|}
\hline & FAMÍLIA & $\begin{array}{l}\text { ESPÉCIE } \\
\text { Tabebuia sp. } \\
\text { Tipo }\end{array}$ \\
\hline & BIXACEAE & Bixa orellana \\
\hline & BOMBACACEAE & $\begin{array}{l}\text { Ceiba pentandra } \\
\text { Pachira aquatica }\end{array}$ \\
\hline & s & Tipo \\
\hline & BORRAGINACEAE & $\begin{array}{l}\text { Cordia sp. } \\
\text { Cordia tipo }\end{array}$ \\
\hline & BURSERACEAE & Protium sp. \\
\hline & CAESALPINIACEAE & $\begin{array}{l}\text { Aldina sp. } \\
\text { Bauhinia sp. } \\
\text { Cassia latifolia } \\
\text { Cassia sp. } \\
\text { Cynometra sp. } \\
\text { Swartzia sp. } \\
\text { Tipo }\end{array}$ \\
\hline & CECROPIACEAE & Cecropia sp. \\
\hline हे & CLUSIACEAE & $\begin{array}{l}\text { Symphonia sp. } \\
\text { Tipo }\end{array}$ \\
\hline h & & Vismia sp. \\
\hline & COMBRETACEAE & Tipo \\
\hline 9 & CONVOLVULACEAE & Ipomoea sp. \\
\hline
\end{tabular}

1987

1988

1989

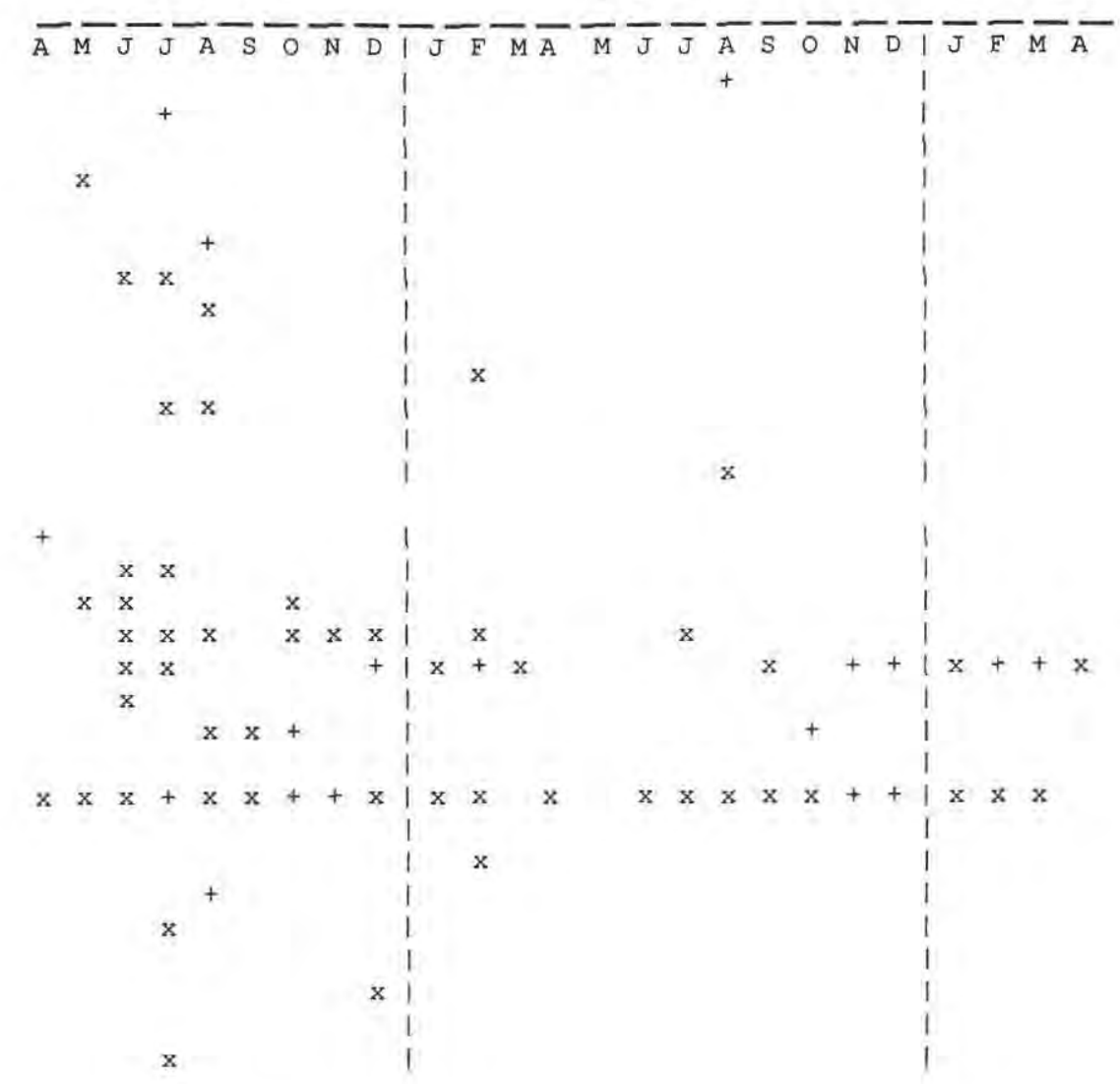


Cont. Tabela 1

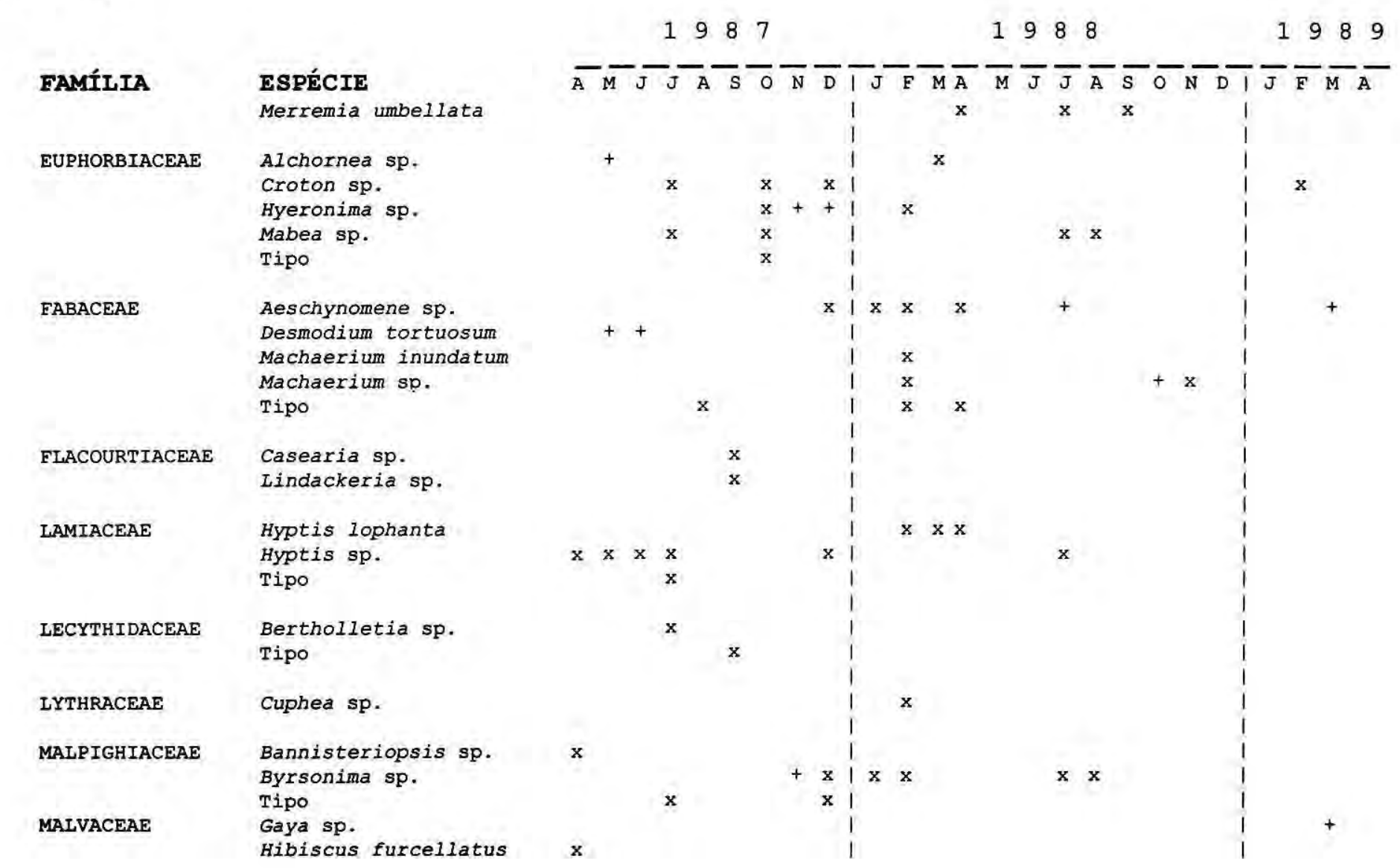


Cont. Tabela 1

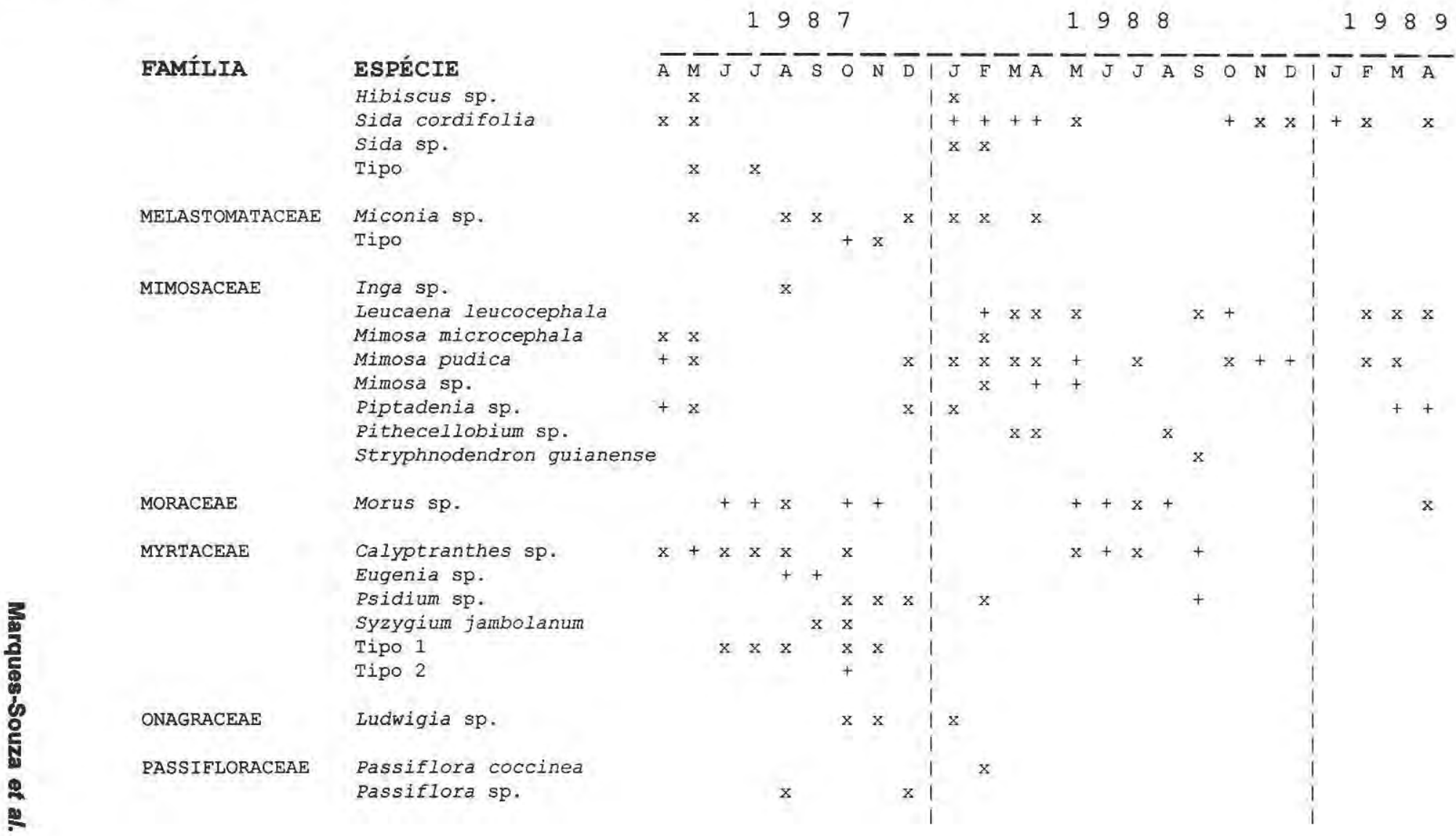


Cont. Tabela 1

\section{FAMÍLIA \\ PIPERACEAE}

POACEAE

POLYGALACEAE

POLYPODIACEAE

PORTULACACEAE PROTEACEAE

RUBIACEAE

RUTACEAE

SALICACEAE

SAPINDACEAE

SAPOTACEAE

SOLANACEAE

TURNERACEAE

\section{ESPÉCIE}

Piper hispidum Piper sp.

Piperonia sp.

Tipo 1

Tipo 2

Tipo

Tipo

Talinum racemosum Roupala montana

Borreria sp. Tipo

Zanthoxylum sp.

Salix sp.

Tipo

Tipo 1

Tipo 2

Solanum myrianthum solanum sp.

Piriqueta cistoides
1987

1988

19889

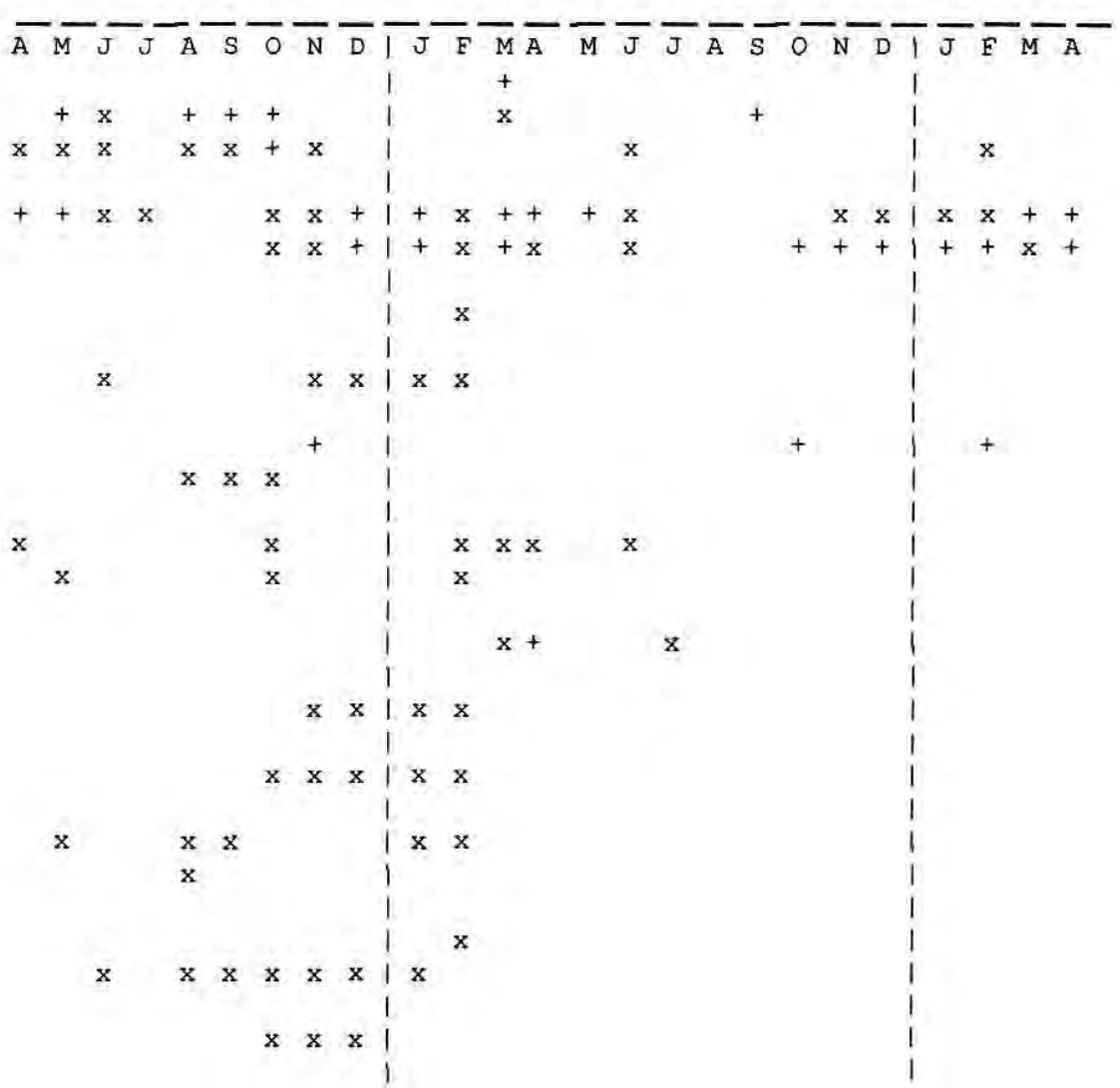




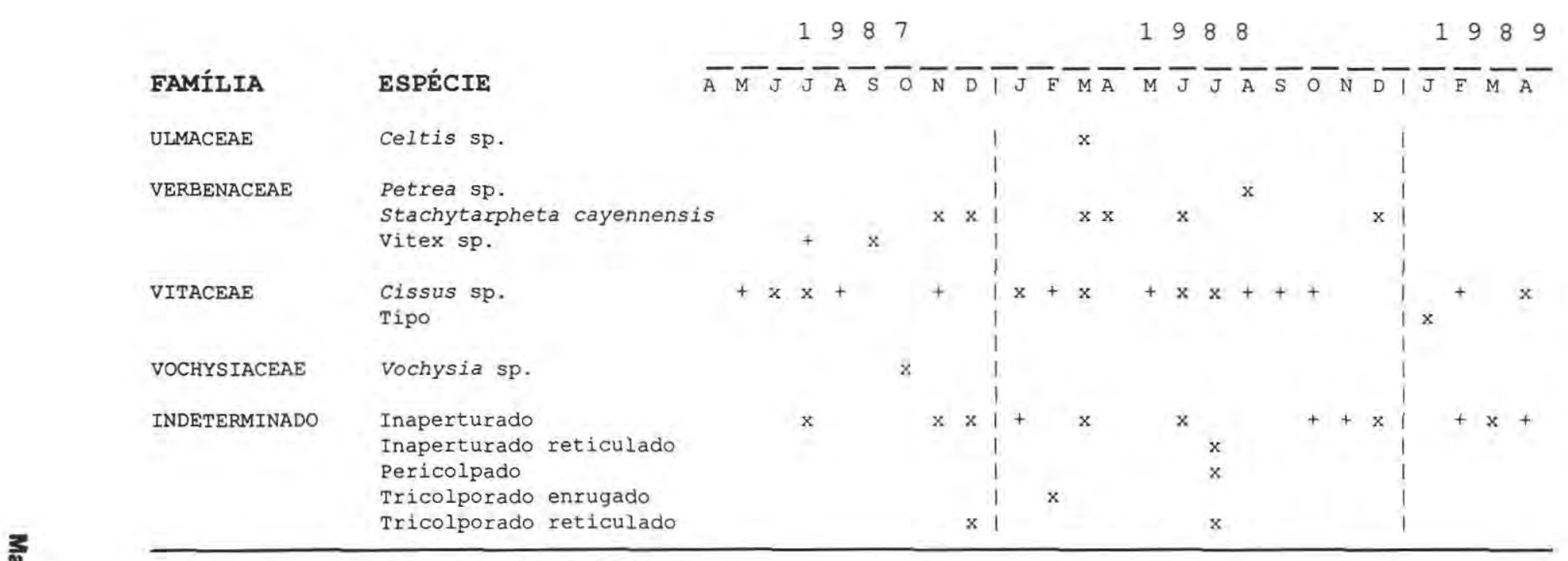

(+) Espécie/dominante

(x) Espécie/visitada 
de 1987; janeiro, março, setembro, outubro, novembro e dezembro de 1988; abril de 1989) espécie/ dominante $(+)$. Outras duas espécies da família Asteraceae foram bastante coletadas. Asteraceae tipo, que teve seu pólen coletado em treze meses, sendo oito meses em 1987 (abril a dezembro) e cinco meses em 1988 (janeiro, fevereiro, junho, agosto e outubro), e Emilia sonchifolia que foi coletada em oito meses, dos quais janeiro e outubro de 1988 como espécie/dominante(+); agosto, outubro e dezembro de 1987; e fevereiro de 1988 como espécie/ visitada(x). Já a família Caesalpiniaceae teve, Cynometra sp., como a espécie mais procurada pelas operárias. Foram treze meses que essa espécie teve seu pólen coletado, dos quais sete meses (junho e julho de 1987; janeiro, março e setembro de 1988; janeiro e abril de 1989) como espécie/visitada(x) e em seis meses (dezembro de 1987; fevereiro, novembro e dezembro de 1988; fevereiro e março de 1989) como espécie/dominante $(+)$. Ainda dentro dessa família Cassia sp. foi coletada em oito meses, sendo seis meses de 1987 (junho, julho, agosto, outubro novembro e dezembro) e dois meses de 1988 (fevereiro e julho) sempre como espécie/visitada(x).

As famílias Malvaceae e Myrtaceae tiveram cada seis espécies coletadas. Sida cordifolia foi a espécie da família Malvaceae cujo pólen foi coletado durante treze meses. Desse total, dois meses em 1987 (abril e março) como espécie/visitada( $\mathrm{x}$ ); cinco meses de 1988 (janeiro, fevereiro, março, abril e outubro) como espécie/ dominante $(+)$; e três meses de 1988 (maio, novembro e dezembro) como espécie/visitada(x). Em 1989, Sida cordifolia, foi coletada em janeiro, sendo espécie/dominante $(+)$, e nos meses de fevereiro e abril, sendo espécie/visitada(x). Da família Myrtaceae, Calyptranthes sp., foi coletada durante dez meses, sendo que em sete meses (abril, junho, julho, agosto e outubro de 1987; maio e julho de 1988) como espécie/visitada(x) e em três meses (março de 1987; junho e setembro de 1988) como espécie/ dominante(+). Ainda dentro dessa família, Myrtaceae tipo 1 teve seu pólen coletado durante cinco meses (junho, julho, agosto, outubro e novembro de 1987) sendo espécie/ visitada(x). Já Psidium $\mathrm{sp}$. também foi coletada em cinco meses, sendo quatro meses (outubro, novembro, dezembro de 1987 e fevereiro de 1988) como espécie/visitada(x) e o mês de setembro de 1988 como espécie/dominante(+).

Com cinco espécies de plantas coletadas vem a família Fabaceae. Dessas espécies, Aeschynomene sp. foi coletada durante seis meses, dos quais quatro meses (dezembro de 1987; janeiro, fevereiro e abril de 1988) como espécie/visitada(x) e em dois meses (julho de 1988 e março de 1989) como espécie/dominante(+). A espécie Desmodium tortuosum teve seu pólen coletado nos meses de maio e junho de 1987 como espécie/dominante(+). As outras três espécies dessa família foram pouco coletadas. 
A familia Euphorbiaceae também teve cinco espécies coletadas pelas Apis, sendo pequena a freqüência dos meses que cada espécie teve o seu pólen coletado. Dentre elas, três espécies foram coletadas durante quatro meses. Foram elas: Croton sp., Hyeronima sp. e Mabea sp. Dessas, apenas Hyernonima sp. foi espécie/ dominante $(+)$ nos meses de novembro e dezembro de 1987 , enquanto as duas outras espécies foram espécie/ $\operatorname{visitada}(\mathrm{x})$.

Individualmente algumas plantas merecem uma atenção especial, devido a quantidade de meses que foram coletadas. Destacam-se entre elas $\mathrm{Ce}$ cropia sp., que foi coletada durante 22 meses, exceto nos meses de março, maio de 1988 e abril de 1989 , sendo que em cinco meses (julho, outubro e novembro de 1987; novembro e dezembro de 1988) foi espécie/ dominante $(+)$. As outras espécies foram: Poaceae tipo 1, que foi coletada em 19 meses, sendo que em nove meses (abril, maio, dezembro de 1987; janeiro, março, abril, maio de 1988 ; março e abril de 1989) como espécie/ dominante(+); Cissus sp., que foi coletada em 16 meses, dos quais nove meses (abril, julho, novembro de 1987; fevereiro, maio, agosto, setembro, outubro de 1988 e fevereiro de 1989) como espécie/dominante(+); Poaceae tipo 2, que teve seu pólen coletado em 15 meses, sendo que em nove meses (dezembro de 1987; janeiro, março, outubro, novembro, dezembro de 1988 ; janeiro, fevereiro e abril de 1989) como espécie/dominante (+); Amaranthus sp., coletada em dez meses, sendo espécie/dominante $(+)$ em três meses (novembro de 1987; janeiro e fevereiro de 1988); Morus sp., também teve seu pólen coletado em dez meses sendo espécie/dominante $(+)$ em sete meses (junho, julho, outubro, dezembro de 1987; maio, junho e agosto/1988); Piperonia sp., que foi coletada em nove meses, dos quais oito meses como espécie/visitada (x) e um mes (outubro de 1987) como espécie/dominante(+); Miconia sp. e Solanum sp. que foram coletadas em sete meses, ambas espécie/visitada(x); Hyptis sp., Byrsonima sp. e Stachytarpheta cayennensis, que tiveram seus pólen coletados em seis meses.

Com relação ao período da coleta, constatou-se que de um total de 400 amostras, fevereiro de 1988 foi o mês onde as operárias mais diversificaram na coleta de tipos polínicos (Tab. 2). Foram $41(7,5 \%)$ espécies vegetais que tiveram seus pólen coletados distribuídos em 26 famílias (7,3\%). Já novembro de 1988 e janeiro de 1989 , foram os meses com menor incidência de coleta por parte das Apis com onze $(2,0 \%)$ tipos polínicos coletados em cada mês distribuídos em cinco $(1,4 \%)$ e sete $(2,0 \%)$ famílias de plantas, respectivamente.

\section{DISCUSSÃO}

Pelos dados obtidos, observou-se que o ano de 1987 foi onde as operárias mais diversificaram e, conseqüentemente, mais tipos polínicos foram coletados. Essa tendência na diversificação polínica continuou até 
Tabela 2. Distribuição mensal dos tipos polínicos coletados por Apis mellifera em Ji-Paraná (RO).

\begin{tabular}{|c|c|c|c|c|c|c|}
\hline Ano & Mes & $\begin{array}{c}\text { Número } \\
\text { de } \\
\text { amostras }\end{array}$ & $\begin{array}{l}\text { Total de } \\
\text { espécies } \\
\text { coletadas }\end{array}$ & $\%$ & $\begin{array}{l}\text { Distr. } \\
\text { por } \\
\text { familia }\end{array}$ & $\%$ \\
\hline $\begin{array}{l}1 \\
9 \\
8 \\
7\end{array}$ & $\begin{array}{l}\text { Abril } \\
\text { Maio } \\
\text { Junho } \\
\text { Julho } \\
\text { Agosto } \\
\text { Setembro } \\
\text { Outubro } \\
\text { Novembro } \\
\text { Dezembro }\end{array}$ & $\begin{array}{l}11 \\
22 \\
19 \\
22 \\
22 \\
15 \\
21 \\
15 \\
20\end{array}$ & $\begin{array}{l}18 \\
27 \\
26 \\
32 \\
33 \\
22 \\
39 \\
26 \\
35\end{array}$ & $\begin{array}{l}3,3 \\
4,9 \\
4,7 \\
5,8 \\
6,0 \\
4,0 \\
7,1 \\
4,7 \\
6,4\end{array}$ & $\begin{array}{l}13 \\
17 \\
16 \\
21 \\
20 \\
13 \\
19 \\
21 \\
21\end{array}$ & $\begin{array}{l}3,7 \\
4,8 \\
4,5 \\
5,9 \\
5,6 \\
5,4 \\
5,4 \\
5,9 \\
5,9\end{array}$ \\
\hline $\begin{array}{l}1 \\
9 \\
8 \\
8\end{array}$ & $\begin{array}{l}\text { Janeiro } \\
\text { Fevereiro } \\
\text { Março } \\
\text { Abril } \\
\text { Maio } \\
\text { Junho } \\
\text { Julho } \\
\text { Agosto } \\
\text { Setembro } \\
\text { Outubro } \\
\text { Novembro } \\
\text { Dezembro }\end{array}$ & $\begin{array}{l}20 \\
18 \\
15 \\
15 \\
20 \\
12 \\
13 \\
16 \\
12 \\
12 \\
08 \\
12\end{array}$ & $\begin{array}{l}30 \\
41 \\
23 \\
21 \\
12 \\
16 \\
19 \\
15 \\
16 \\
17 \\
11 \\
13\end{array}$ & $\begin{array}{l}5,5 \\
7,5 \\
4,2 \\
3,8 \\
2,2 \\
2,9 \\
3,5 \\
2,7 \\
2,9 \\
3,1 \\
2,0 \\
2,4\end{array}$ & $\begin{array}{l}18 \\
26 \\
16 \\
15 \\
08 \\
11 \\
15 \\
11 \\
10 \\
11 \\
05 \\
09\end{array}$ & $\begin{array}{l}5,1 \\
7,3 \\
4,5 \\
4,2 \\
2,3 \\
3,1 \\
4,2 \\
3,1 \\
2,8 \\
3,1 \\
1,4 \\
2,5\end{array}$ \\
\hline $\begin{array}{l}1 \\
9 \\
8 \\
9\end{array}$ & $\begin{array}{l}\text { Janeiro } \\
\text { Fevereiro } \\
\text { Março } \\
\text { Abril }\end{array}$ & $\begin{array}{l}15 \\
18 \\
15 \\
12\end{array}$ & $\begin{array}{l}11 \\
15 \\
17 \\
13\end{array}$ & $\begin{array}{l}2,0 \\
2,7 \\
3,1 \\
2,4\end{array}$ & $\begin{array}{l}07 \\
12 \\
09 \\
10\end{array}$ & $\begin{array}{l}2,0 \\
3,4 \\
2,5 \\
2,8\end{array}$ \\
\hline TOTAL & & 400 & - & $100 \%$ & - & $100 \%$ \\
\hline
\end{tabular}

fevereiro de 1988 , mês no qual foi registrado a maior quantidade de espécies de plantas coletadas, num total de 41, sendo sete de espécie/dominante(+) e 34 de espécie/visitada(x). Nos meses seguintes houve uma certa estabilização na quantidade de espécies coletadas, com intervalos de aumento e queda nas coletas (Fig. 2).

No total foram coletados pelas operárias o pólen de 126 espécies de plantas, distribuídas em 87 gêneros e 47 familias durante os dois anos de estudo. A família Arecaceae foi a que teve o maior número de espécies coletadas, num total de onze. Dessas palmeiras duas existiam em grande quantidade dentro da área da Escola
Agrícola, compondo a parte baixa do terreno alagável. São elas: Euterpe precatoria e Mauritia flexuosa. Ambas foram coletadas pelas operárias em sete e doze meses, respectivamente. Mas, as espécies dessa família que mais meses tiveram seus pólen coletados foram Cocos nucifera (com 15 meses) e Orbignya martiana (com 21 meses) as duas espécies introduzidas na área da Escola.

Alguns autores observaram que as palmeiras são importantes fontes de pólen, tanto para as Apis, como para outras espécies de abelhas principalmente os meliponíneos (ENGEL \& DINGEMANS-BAKELS, 1980; ABSY et al., 1984; ROUBIK et 


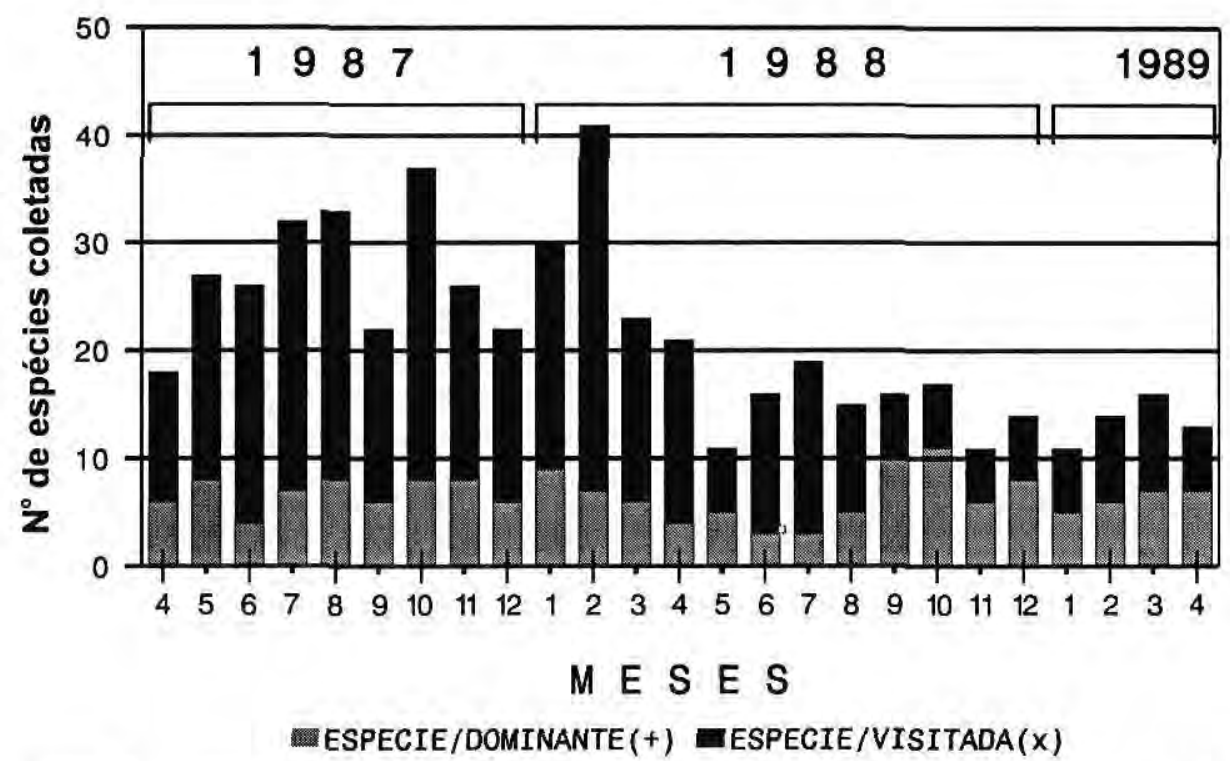

Figura 2. Dados mensais da coleta de pólen por Apis mellifera em Ji-Paraná(RO) no período de dois anos.

al., 1986; KERR et al., 1986/87; IMPERATRIZ-FONSECA et al., 1989; RAMALHO et al., 1990; AMBOUGOU-ATISSO, 1990; MARQUES-SOUZA, 1993). As densas inflorescências presentes nessas plantas quase o ano todo (como em Bactris gasipaes, Cocos nucifera, Elaeis oleifera, Orbignya martiana, Euterpe oleraceae, Mauritia flexuosa entre outras) e, os seus polinizadores, na maioria pequenos curculionídeos, que não apresentam comportamento agonístico em relação as abelhas, faz com que as palmeiras, por todas essas facilidades, sejam uma fonte constante de alimento, principalmente nos períodos de redução sazonal das outras plantas. Tal fato foi constatado por ROUBIK (1990) que observou, em particular, nas palmeiras um importante recurso para as Apis mellifera nos períodos de chuvas na República do Panamá, sendo as espécies pertencentes aos gêneros Bactris, Elaeis, Geonoma, Oenocarpus e Socratea as mais procuradas para a coleta de pólen pelas operárias (ROUBIK, 1991).

Outras espécies vegetais foram bastante representativas, não só pela quantidade de pólen que ofereceram às Apis, como pela quantidade de meses que foram coletadas. Plantas como Alternathera sp., Cosmos caudatus, Asteraceae tipo, Cynometra sp., Cecropia sp., Mimosa pudica, Poaceae tipo 1 e 2 e Cissus sp. foram coletadas pelas Apis em mais de dez meses. Dessas plantas, observamos nas flores de Cosmos caudatus a agressividade com que as operárias forrageavam, formando verdadeiras nuvens negras de abelhas nas flores, monopolizando essa 
fonte de alimento, o que impedia que outras espécies de abelhas se aproximassem, apesar das Apis não serem agressivas com muitos tipos de meliponíneos (ROUBIK, 1980).

Esse modo agressivo de forrageamento dos Apidae sociais, segundo GUIBU et al. (1988), é freqüentemente associado a produtividade das fontes, preferências específicas e o manuseio das peças florais que pode facilitar a coleta do pólen elou néctar. Por exemplo, Bertholletia excelsa e Couratari tenuicarpa são polinizadas por abelhas grandes (Epicharis, Euplusia, Eulaema, etc.), que são capazes de desenrolar o androceu floral, e assim chegar ao pólen (NELSON et al. 1985). Plantas com anteras poricidas dificultam a coleta do pólen, obrigando a vários tipos de abelhas, a recorrerem a outras fontes de alimento ou, então, coletarem por "métodos ilegítimos" como a destruição das anteras (RENNER, 1983). Talvez tenha sido este o empecilho que contribuiu para que Cosmos caudatus e Cecropia sp. tenham tido os seus pólen bastante coletados, enquanto as Cassias, Miconia sp. e Solanum sp. - este último muito cultivado na Escola Agrícola - terem sido pouco explorados. Essas três espécies de plantas possuem anteras poricidas o que obriga os visitantes a desenvolverem estratégias na hora da coleta, como vibrar as anteras (buzz pollination), para liberar o pólen. É o caso de Centris, Epicharis, Xylocopa, Bombus, Euglossa, Eulaema,
Melipona, etc. abelhas que utilizam o método de vibração das anteras, o que já não ocorre com as Apis (BUCHMANN, 1983).

Em todos os levantamentos de flora apícola vai ficando cada vez mais evidente uma certa similaridade existente entre algumas espécies de plantas coletadas pelas abelhas. Plantas como Cecropia sp., Mimosa sp., Leucaena sp. e outras pertencente as famílias Myrtaceae, Arecaceae, Caesalpiniaceae, Asteraceae e Poaceae estão presentes em levantamentos feitos tanto com operárias de Apis como em meliponíneos. ABSY et al. (1980) observaram que as mimosas e Cecropia sp. são utilizadas por duas espécies de Melipona da Amazônia tanto para pólen como para néctar, o que não foi diferente das observações de ENGEL \& DINGEMANS-BAKELS (1980) com alguns meliponíneos no Suriname; de RAMALHO et al. (1985) com operárias de Plebeia remota e IMPERATRIZ-FONSECA et al. (1989) com várias espécies de meliponíneos na região de São Paulo.

Quanto as Apis é curioso constatar que em dois anos de estudo, consecutivos, Cecropia sp. teve seu pólen coletado pelas campeiras em 22 meses dos quais cinco como espécie/ dominante $(+)$ (Tab. 1). Essa planta é invasora e substitui rapidamente a vegetação original de áreas perturbadas. Na Amazônia como são cada vêz mais intensas as grandes derrubadas e/ou queimadas e em seguida o abandono da área pelos colonos, as Cecropias, que crescem de 
9-12 m em três anos, vão tendo um campo vasto para se proliferar e, com isso, vão se tornando uma opção alimentar para as Apis pois, além da fácil proliferação, essa planta floresce $o$ ano todo.

Quanto ao período de coleta, observou-se que Cecropia sp. teve seu pólen mais intensamente coletado pelas operárias nos meses de outubro e novembro de 1987 e, novamente, em novembro e dezembro de 1988 , período semelhante observado por CORTOPASSI-LAURINO $\&$ RAMALHO (1989) com Apis em São Paulo. Talvez essa coincidência de meses em que Cecropia sp. foi coletada nos dois anos, esteja relacionada com uma maior oferta de pólen dessa planta e diminuição das outras fontes, nesses meses de período seco na região, onde se registra os picos de floração dessa espécie. As operárias aproveitaram-se dessa maior oferta de pólen das Cecropias, beneficiadas pelo raio de ação onde se encontravam essas plantas, exploraram intensamente esse alimento, e com isso economizaram energia entre o percurso fonte/colméia.

Outras espécies como Cynometra sp., Poaceae tipo 1 e 2 e Cissus sp. foram bem coletadas, mesmo que em meses alternados. Sobre a família Poaceae, CORTOPASSI-LAURINO \& RAMALHO (1989) constataram que o pólen anemófilo das espécies dessa família são bastante coletados pelas Apis nos meses de janeiro, fevereiro, maio e junho. Em nosso estudo observou-se que apesar de duas espécies de Poaceae terem sido coletadas em 19 e 15 meses, respectivamente, foram justamente nos meses de dezembro, janeiro, março e abril onde houve uma incidência de coleta do pólen de espécies de Poaceae.

Apesar das Apis terem coletado pólen de 126 espécies de plantas, o que se pode observar no geral, é que as operárias se ativeram a coletar intensamente em poucas fontes, haja visto que apenas 15 plantas $(12,0 \%)$ tiveram seus pólen coletados em mais de dez meses durante os dois anos; 24 plantas $(19,0 \%)$ foram coletadas entre cinco e nove meses; e 87 plantas $(69,0 \%)$ foram coletadas entre um e quatro meses. Provavelmente essa generalidade apresentada pelas Apis esteja mais relacionada com o curto período de floração da maioria dessas plantas, do que a outros fatores externos como, por exemplo, a competição pelo mesmo alimento com outros visitantes, devido a eficiência apresentada pelas africanizadas na hora da coleta do pólen.

\section{Referências bibliográficas}

ABSY, M.L.; BEZERRA, E.B.; KERR, W.E. 1980. Plantas utilizadas por duas espécies de Melipona da Amazônia. Acta Amazonica, 10(2): 271-281.

ABSY, M.L.; CAMARGO, J.M.F.; KERR, W.E.; MIRANDA, I.P.A. 1984. Espécies de plantas visitadas por Meliponinae (Hymenoptera; Apoidea), para a coleta de pólen na região do médio Amazonas. Rev. Brasil. Biol., 44(2):227-237.

AMBOUGOU-ATISSO, V. - 1990. Analyse pollinique des réserves alimentaires d' Apis mellifica adansonii Lat.et d' Hypotrigona sp. (Hym. Apidae sociaux) 
de la région de Makokou (N-E Gabon). Bull. Soc. Bot. Fr. 137, Actual. Bot., (2):166-169.

BUCHMANN, S.L. 1983. Buzz pollination in Angiosperms. In: Handbook of Experimental Pollination Biology. Scientific and Academic Editions, New York, p.73113.

CORTOPASSI-LAURINO, M. 1982: Divisão de recursos tróficos entre abelhas sociais principalmente em Apis mellifera Linné e Trigona (Trigona) spinipes Fabricius (Apinae, Hymenoptera). Tese de Doutoramento, Instituto de Biociências, Universidade de São Paulo. 180 p.

CORTOPASSI-LAURINO, M.; RAMALHO, M. 1989. Pollen harvest by africanized Apis mellifera and Trigona spinipes in São Paulo botanical and ecological views. Apidologie, 19(1):1-24.

ENGEL, M.S.; DINGEMANS-BAKELS, F. 1980. Nectar and pollen resources for stingless bees (Meliponinae, $\mathrm{Hy}$ menoptera) in Surinam (South America). Apidologie, 11(4):341-350.

ERDTMAN, G. 1960. The acetolisys method in a revised description. $S v$. Bot. Tidskr., Lund. 54(4):561-564.

GUIBU, L.S.; RAMALHO, M.; KLEINERTGIOVANNINI, A.; IMPERATRIZFONSECA, V.L. 1988. Exploração dos recursos florais por colônias de Melipona quadrifasciata (Apidae, Meliponinae). Rev. Brasil. Biol., 48(2):299-305.

IMPERATRIZ-FONSECA, V.L.; KLEINERTGIOVANNINI, A.; RAMALHO, M. 1989. Pollen harvest by eusocial bees in a non-natural community in Brazil. Journal of Tropical Ecology, 5:239-242.

KERR, W.E. 1967. The history of the introduction of African bees to Brazil. $S . A$. Bee Journal, 39:3-5.

KERR, W.E.; ABSY, M.L.; MARQUESSOUZA, A.C. 1986/87. Espécies nectaríferas e poliníferas utilizadas pela abelha Melipona compressipes fasciculata (Meliponinae, Apidae), no Maranhão. Acta Amazonica, 16/17(n.
(ब19único):145-156.7วT3.

MARQÜES-SOUZA, A.C. 1993. Espécies de plantas visitadas para a coleta de pólen por cinco tipos de Meliponineos da Amazônia. Dissertação, UFAM/INPA, Manaus, $114 \mathrm{p}$.

NELSON, B.W.; ABSY, M.L.; BARBOSA, E.M.; PRANCE, G.T. 1985. Observations

तis on flower visitors to Bertholletia excelsa H.B.K. and Couratari tenuicarpa A.C. SM. (Lecythidaceae). Acta Amazonica, Supl., 15(1-2):225-234.

NOGUEIRA-NETO, P. 1962. $O$ inicio $d a$ apicultura no Brasil. Secretaria de Agricultura S.P.

RAMALHO, M.; IMPERATRIZ-FONSECA, V.L.; KLEINERT-GIOVANNINI, A.; CORTOPASSI-LAURINO, M. 1985. Exploitation of floral resources by Plebeia remota Holmberg (Apidae, Meliponinae). Apidologie, 16(3): 307-330.

RAMALHO, M.; KLEINERT-GIOVANNINI, A.; IMPERATRIZ-FONSECA, V.L. 1990. Important bee plants for stingless bees (Melipona and Trigonini) and Africanized honeybees (Apis mellifera) in neotropical habitats: a review. Apidologie, 21: 1-20.

RENNER, S. 1983. The widespread ocurrence of anther destruction by Trigona bees in Melastomataceae. Biotropica, 15(4):251256.

ROUBIK, D.W. 1980. Foraging behavior of competing africanized honeybees and stingless bees. Ecology, 61(4):836-845.

ROUBIK, D.W.; MORENO, J.E.; VERGARA, C.; WITTMANN, D. 1986. Sporadic food competition with the African honeybee: projected impact on neotropical social bees. Journal of Tropical Ecology, 2: 97. 111.

ROUBIK, D; BOREHAM, M. 1990. Learn" ing to live with africanized honeybew. Interciencia, 15(3):146-153.

ROUBIK, D.W. 1991. Aspects of africanized honey bee ecology in Tropical America. In: The "African" Honey Bee. Ed. 
SPIVAK, M; FLETCHER, D.J.C.; BREED,

M.D., San Francisco, Oxford. Westview

Press, p. 259-281.

(Aceito para publicação em 22/3/93) 